\title{
Characteristics of the Monographic Scholarship of Foreign Literary Studies by Native Speakers of English John Cullars
}

This study's aim was to determine how scholars who are native speakers of English approach writing monographs on foreign literary topics and to compare these findings to those of the author's earlier study of the monographic literature of English and American literature and of the journal literature of the humanities. All references were tabulated for 30 monographs-15 prizewinners and 15 randomly selected nonprizewinners in the same Dewey classes.

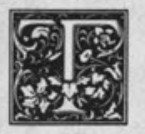

HIS STUDY'S AIM IS to determine how scholars compose monographs dealing with foreign literary subjects and to compare these findings to those of studies of both the monographic and the journal literature of the humanities and related social sciences such as history. This project seeks to determine the nature (book, journal article, manuscript, thesis) and the chronological spread of the bibliographical sources cited by native speakers of English in preparing studies of foreign literature in English. Further distinctions are made as to the language of the cited item, whether it is a primary or secondary source, and whether it is a self-citation.

All references, including implicit citations in the text that are not formally cited, are tabulated for 2 samples of monographs, 15 prizewinning books reported in Publishers Weekly's annual list of literary and publishing awards and 15 nonprizewinning books drawn from the same Dewey classifications and with the same period of publication as the prizewinners.
These nonprizewinners are randomly selected from American Book Publishing Record.

The Publishers Weekly list of annual prizes was chosen because it provides a wide spectrum of awards in all areas of scholarly publication with some prizes specific to a genre of scholarly endeavor and others more broadly based in the humanities and social sciences. These prizes include the American Book Awards, the Alice and Edith Hamilton Award, the Modern Languages Association of America Award, the Christian Gauss Award, the Phi Beta Kappa Book Award, the James Russell Lowell Prize, the Morris J. Kaplun Memorial Award, the Pulitzer Prize, the British National Book Award, the National Book Critics Circle Award, and the George Freedly Memorial Book Award. This wide spectrum of awards was preferred to more narrowly academic awards for specialist monographs. While some specialist monographs are chosen for the prizes reported by Publishers Weekly, a monograph examining a broader

John Cullars is Bibliographer for the Humanities at the University of Illinois, Chicago, Illinois 60680.

I would like to acknowledge the help of my colleague Stephen E. Wiberley, Jr., in the preparation of this manuscript. 
or more popular topic is apt to be ignored by the more strictly academic prize committees.

The data thus gathered are compared and contrasted to findings concerning both the monographic and the journal literature of the humanities to determine whether patterns of scholarship shown in the preparation of monographs on foreign literature differ from those shown in the preparation of studies of American or British literature. Books are divided between prizewinners and nonprizewinners to learns what distinctions, if any, obtain between the scholarly practices of authors whose scholarship is acknowledged by their peers through the receipt of prestigious awards and those whose works lack such recognition.

This study seeks to determine if certain traits or patterns of scholarship in the preparation of manuscripts that are found more frequently among prizewinning authors than among nonprizewinners can be isolated. The author's 1985 study of the monographic literature of British and American literary studies found significant differences in scholarly practices between books that won prizes and those that did not. Prizewinners were longer, cited many more sources, and cited manuscripts much more frequently than did nonprizewinning book or journal articles. While both types of monographs and journal articles in the humanities cited books more heavily than any other type of source, more than $37 \%$ of prizewinning monographic references were to articles, manuscripts, or theses. Prizewinners also exhibited a more even spread of references chronologically than did nonprizewinners. ${ }^{1}$

Combining the results of this study with those of the author's previous work on the monographic scholarship of English and American literature provides a tentative sketch of the shape of English-language monographic publication dealing with literary criticism of both English-language and foreign literatures by native speakers of English. Collection development officers and bibliographers require more than ever a heightened grasp of the shape of the disciplines entrusted to them in times of fiscal austerity marked by dissatisfaction with library strategies to serve the research needs of scholars. A 1985 survey of 3,825 scholars in the humanities and social sciences revealed that $52 \%$ of the researchers surveyed relied upon interlibrary loan and $77 \%$ upon the personal acquisition of needed sources, particularly of a serial nature, rather than on local library holdings in meeting their research needs. ${ }^{2}$

While many scholars have examined the journal literature of all disciplines, they have paid less attention to monographs, presumably for lack of a convenient methodology allowing the examination of a large enough sample to provide statistical validity for its projections. Workable studies must limit themselves to such small sample populations that only tendencies may be isolated. In these two articles on the monographic literature findings are compared to earlier studies of the journal literature of the humanities, including history, the social science most frequently treated as akin to the humanities.

These monographic literature studies differ in one important respect from the studies of the journal literature of the humanities and history consulted in this project. The latter were citation studies in which any source was tabulated only once regardless of how frequently the author cited it. While such a procedure may be appropriate for the study of journal articles, it would misrepresent the value of frequently cited sources and would skew the weighting of the decades where they appeared in the chronological survey. Standard editions of texts, collected letters, manuscript collections, autobiographies, standard biographies, and memoirs are basic tools for humanistic research, while the sciences or the social sciences draw more heavily on survey or experimental studies. Counting these much cited works as single citations minimizes the important distinctions between the patterns of research in the humanities and other disciplines. Thus, this is a reference study where each reference is tabulated as frequently as it occurs. This practice has the limitation that the comparisons made between these two reference studies of humanities monographs 
and citation studies of the journal literature of the humanities may be misleading, even while seeming mutually supportive.

While the previous study of monographs did not isolate foreign from English-language references, the author's admittedly subjective impression is that relatively few of the references were to foreign sources, even though any cursory examination of the annual MLA bibliographies will confirm that there is no dearth of foreign-language scholarship on English and American literary topics. The inference to be drawn is that most Englishspeaking scholars ignore the bulk of this foreign research, and studies of journal articles show that to be the case for the journal literature.

Studies demonstrate that most scientists and many social scientists dismiss non-English-language research as irrelevant in the face of the quantity and the quality of relevant English-language publications. This study addresses such questions as whether the same types of publishers issue monographs on both American and British literature and on foreign-language literature. This article also examines the attitudes toward the need to master foreign languages and the use of translations, summaries, and abstracts by literary scholars who are native speakers of English.

\section{BACKGROUND}

In 1979, Charles B. Osburn documented the ever-growing emphasis on Englishlanguage scholarship in the scholarly community throughout the world since the end of World War II. He found that the number of citations in The Annual Bibliography of English Language and Literature had increased from 4,994 in 1937 to 13,044 in 1972 with no comparable explosive growth rate for romance philology in the same period. ${ }^{4}$ The most recent (1982) edition of this reference tool shows 14,242 citations. A comparable check of the MLA Bibliography between 1973 and 1984 shows an increase in the number of citations to English and American literature and a decline in the number of citations to the romance language literatures. In 1973, there were 9,272 citations in the MLA Bibliogra- phy for English and American literature and 8,911 for that of the Romance languages. In the 1984 volume, one finds 11,302 citations to English and American literature and only 8,042 to that of the Romance languages. Of course, English citations to foreign topics appear with the foreign sections and vice versa, but it still seems clear that English and American literary scholarship outdistances that of the Romance languages. Indeed, English and American literary studies account for $40.5 \%$ of all the world's literary criticism in any language listed in the 1984 MLA Bibliography.

\section{"... English and American literary studies account for $40.5 \%$ of all the world's literary criticism in any lan- guage listed in the 1984 MLA Bibliog- raphy."}

Osburn further suggested that, while the humanities are adopting certain techniques and quantitative methodologies from the sciences and social sciences, literary scholarship is more resistant to such tendencies because of necessarily subjective impressions fostered by the very nature of language:

It is doubtful that a concept of historiographic structure can be properly applied to the study of literature, at least not on a national scale, and a survey of professional writing in the field reveals that there is less attention given the matter in literature than in any other academic area. The study of literature is more closely related to an understanding of language than any other field, since literature is a recorded form of verbal self-expression. A natural consequence of this is the intrusion of ideologies and cultural perspectives along nationalist lines into the study of literature. ${ }^{5}$

Scholarly publishing in the United States rose from under $35 \%$ of the total domestic publication in 1950 to over $46 \%$ in 1976 , and statistics such as those quoted by Osburn continue to reflect the everyincreasing importance of Englishlanguages research worldwide in all disciplines. This American (and other 
English-language) scholarship has progressively dominated the research activities of English-speaking academics, since scientists and many social scientists perceive the most significant research as being mainly in English.

In W. T. Hutchin's 1971 British study, when asked if they suspected that they were missing important non-Englishlanguage research, $23 \%$ of humanities scholars answered "probably"; $28.2 \%$, "possibly"; 27.4\%, "unlikely"; and $18.8 \%$ answered "no." Fully $64 \%$ of the social scientists and $24.8 \%$ of the humanists believed that all vital research appeared in English, English translation, or summary within four years of publication. These scholars also ranked research done in non-English-speaking areas as less important than that done in the United States, the United Kingdom, and the Commonwealth. Only $11.1 \%$ of the scholars surveyed by Hutchins could read all foreign languages relevant to their research, but $10.2 \%$ claimed to have too much English criticism to read to consider foreign scholarship. ${ }^{6}$

The value of translations is not ranked highly by scholars in any discipline. Scientists and social scientists prefer review articles, abstracts, or summaries as quicker, more economical guides to foreign publication, and even in the humanities, where a researcher's style or the minutiae of the argument might be expected to be more highly valued, translations are not championed. Moreover, countries with a strong nationalist pride in their languages and where few other languages are spoken on a wide scale, such as the United States, Great Britain, or France, tend to be openly suspicious of translations. ${ }^{7}$ In the United States, even university presses are increasingly wary of publishing translations; they state that books of wide interest should be published by trade presses, while books of special interest are too dubious a prospect commercially for houses that publish only 70 or so titles a year.

According to Kitty Harmon, it is harder now to publish translations than in the 1960s, a time of relative financial stability and prosperity. Even rave reviews led to the sale of no more than one-third of the first printing of translations, while the work of first-rate translators is becoming more expensive. ${ }^{8}$ Herbert Bailey, Jr., observes that studies of foreign language topics in the humanities are apt to be restricted to the following categories: single works of literature, less well-known or premodern authors, linguistics and philosophy-all areas avoided by commercially minded publishers.

\section{METHODOLOGY}

Since the Art \& Humanities Citation Index does not tabulate citations for monographs, a study of monographic literature reference patterns required the examination of each monograph to check all footnotes or endnotes and to skim each page for implicit references. The laborintensive nature of the methodology, with its page-by-page examination of each book and the notation of each reference in several categories, led to the decision to restrict the sample to 30 books. While there can be no guarantee that all implicit references were found, every effort was made to locate them. Obviously, however, this was a more subjective process than tabulations of explicit references.

To qualify for this study, a book had to contain footnotes or endnotes, though not necessarily a formal bibliography, and its topic had to be a literary subject either completely or predominantly foreign. Eleven of the prizewinning books and thirteen of the nonprizewinning books dealt exclusively with foreign topics, while the other monographs devoted well over half of their pages to foreign authors, works, or international literary movements.

The language in which a literary work is written logically determines the dominant language of the criticism devoted to it, given the presence of a thriving literary culture in that tongue. This study seeks to determine if English-speaking critics cite a disproportionate percentage of Englishlanguage sources rather than those in the language of the original work or other foreign languages. Since a study of comparable citation patterns by foreign critics must await a later study, no definitive comparisons can be offered here. 
Caution was the byword in selecting these books. Each author had to be a native speaker of English. Authors' backgrounds were investigated through biographical information included in the books themselves, biographical directories, and reviews. If the pertinent information could not be found, the author was excluded. Authors with foreign surnames were excluded unless it was possible to establish that they had not grown up in bilingual homes. The purpose of this part of the study is to determine the citation patterns to foreign sources by scholars who had to learn foreign language(s) through formal training or self-directed study, not through the natural home environment. Textbooks were excluded, as were collections of essays.

To select the nonprizewinning monographs, OCLC was used to find the Dewey numbers of all the prizewinners, and the pages where these Dewey categories appeared in The American Book Publishing Record were put in numerical sequence. Two random numbers were then chosen separately from a random-number table, the first for the page number and the second for the position of the item on the page. If a book had to be rejected as out-ofscope, the next book on the page that fit the criteria was chosen.

\section{". . . this study documented few real distinctions between prizewinning and nonprizewinning books. . . .'}

In most respects, this study documented few real distinctions between prizewinning and nonprizewinning books, unlike the situation with American and British literature in the author's earlier study. Likely explanations concern the nature of scholarly publishing and will be discussed in a later section. In the presentation of data, results will be limited to those drawn from the total sample of 30 books except for those few cases in which noteworthy distinctions do exist between prizewinning and nonprizewinning books.

\section{"The mean number of references per book was 616 , of which 362 were for- eign."}

Each explicit reference was tabulated in terms of (1) its source (monograph, journal article, manuscript, thesis or dissertation), (2) its language, (3) whether it was a primary or secondary source, (4) whether it was a self-citation, and (5) the decade in which the reference was published. The year could not be assigned for implicit references because such references are usually to classic works existing in many editions. Thus the implicit references figure in the total by source, which can usually be inferred from the context, and by language, but not by decade.

\section{RESULTS}

The number of pages in the books sampled ranged from 163 to 495 pages (and one book with 1,051 pages). The mean number of pages was 295 pages, or 268 without the atypically long volume. The number of references within the books ranged from 184 to 1,719 , including implicit citations that made up $3.5 \%$ of the total. While 18 books contained implicit citations, only 4 had as many as $10 \%$ implicit citations. The total number of citations was 18,481 of which 11,843 were references to foreign sources. The mean number of references per book was 616, of which 394 were foreign. Sixteen books had fewer than 500 references and 4 had more than 1,000 . The total sample had a mean of 2.11 references per page, of which 1.34 were foreign references. Sixteen of the monographs had more than 2 references per page, but only 3 had as many as 2 foreign references per page.

The data are analyzed by (1) the percentage of references to the form of the source and (2) by the chronological period in which the cited work was published, with further subdivisions for the percentages of foreign references, individual foreign languages cited, primary sources, and selfcitations. This study treats a reference to 
an article cited in a collection of essays as a monographic reference because the author cited it from a book. Newspaper, magazine, and conference proceedings count as journal articles. Unpublished interviews, telephone conversations, lecture notes, and unpublished correspondence are treated as manuscripts, as is any other unpublished source. When an author cites a reprint edition but also lists the date of the original publication, the former date is used for this tabulation rather than that of the first edition. If an author provides bibliographical footnotes listing pertinent additional reading material, these sources are not included in the tabulation. Tallies for percentages of references by chronological period equal less than $100 \%$ because implicit citations figure in the total number of references but are not assigned to decades because their dates of publication cannot be determined. In addition to implicit citations, about $1 \%$ of the footnoted sources omitted the publication date and thus do not figure in the chronological tables.

Table 1 presents the percentages of references cited by form-monograph, journal article, manuscript, or thesis. The percentage given is based on the number of references to a given type of source divided by the total number of references $(18,481)$. The number of references involved in each tally by source is shown in parentheses following the percentages. Thus, to take $81 \%$ for the total sample, all the 15,006 references to books are divided by 18,481 , the total number of references to all sources.
Table 1 also treats all the foreign references, $64 \%$ of the total references, in the same manner. Table 2 further breaks down the foreign references to the individual foreign languages cited. The languages cited in this study, in addition to English, were French, German, Italian, Latin, Spanish, Russian, and Greek. The "other" category consisted of those languages cited in only a single book. Primary sources were separated from secondary sources. For purposes of this research, any literary text, autobiography, memoirs, diaries, letters, manuscripts, or interviews are treated as primary sources insofar as they are written by an author of literary material as opposed to strictly critical, noncreative writing. The critical writings of famous authors who were also practicing critics, such as T.S. Eliot or Paul Valéry, are treated as primary sources, as are the works of such seminal figures of modern Western civilization as Marx, Freud, or Lenin. The sacred texts of religions are also treated as primary texts. Contemporary critics, even when acknowledged to be the head of literary movements or schools, such as Derrida, Barthes, or Lacan, are considered secondary sources, though they may ultimately achieve canonic status. Interviews and memoirs with associates, friends, and families of authors are treated as secondary sources.

Table 3 presents the chronological spread of the topics of these 30 books. Eight of the monographs had subjects confined totally within the twentieth century; 3 within the nineteenth; 3 within the

\section{TABLE 1}

PERCENTAGE OF REFERENCES BY SOURCE

\begin{tabular}{lcc}
\hline \hline & $\begin{array}{c}\text { Total } \\
(18,481 \text { references })\end{array}$ & $\begin{array}{c}\text { Foreign* } \\
(11,843 \text { references })\end{array}$ \\
\hline Books & $81 \%$ & $82.2 \% / 53 \%$ \\
Articles & $(15,006$ references $)$ & $(9,740$ references $)$ \\
Manuscripts & $10.9 \%$ & $11.4 \% / 7 \%$ \\
Theses & $(2,038$ references $)$ & $(1,355$ references $)$ \\
& $(1,347$ references $)$ & $6.2 \% / 4 \%$ \\
& $(728$ references $)$ \\
& $(90$ references $)$ & $.17 \% / .11 \%$ \\
\hline
\end{tabular}

"The first percentage in the "Foreign" column shows what part of the foreign references are accounted for by each type of source. The second percentage shows what part of the total references these foreign citations account for. 
TABLE 2

PERCENTAGES OF INDIVIDUAL FOREIGN LANGUAGES

\begin{tabular}{lccr}
\hline \hline Languages & \% Foreign & \% Total & No. of References \\
\hline French & $31 \%$ & $20 \%$ & (3,714 references in 29 books) \\
German & $15 \%$ & $10 \%$ & $(1,777$ references in 20 books) \\
Russian & $23 \%$ & $15 \%$ & $(2,781$ references in 6 books) \\
Italian & $13 \%$ & $8 \%$ & $(1,514$ references in 14 books) \\
Latin & $5 \%$ & $3 \%$ & (594 references in 16 books) \\
Greek & $2 \%$ & $1 \%$ & (218 references in 9 books) \\
Spanish & $2 \%$ & $1 \%$ & (272 references in 4 books) \\
Other* & $8 \%$ & $5 \%$ & (973 references in 7 books) \\
\hline
\end{tabular}

*Languages cited in only a single book-Danish, Arabic, Hebrew, Swedish, Eskimo, Navajo, Chinese, Japanese, Mayan, Malay, Old English, Scots.

TABLE 3

\section{CHRONOLOGICAL PERCENTAGES*}

\begin{tabular}{llr}
\hline \hline $1950-1982$ & $65.5 \%$ & $(37.6 \%$ foreign $)$ \\
$1920-1950$ & $18.4 \%$ & $(14.2 \%$ foreign) \\
$1890-1920$ & $6.8 \%$ & (5.7\% foreign) \\
Pre-1890 & $4.4 \%$ & (3.9\% foreign) \\
\hline
\end{tabular}

*These percentages total less than $100 \%$ because chronological figures were not available for the implicit citations and certain explicit citations lacking publication dates.

seventeenth; 1 within the sixteenth; 1 within the fourteenth; 2 in antiquity; and 12 that overlapped centuries, sometimes by only a few decades, but sometimes by 2,000 years, as in a study of the poetic lyric mode. Topics stretched chronologically from Demosthenes (active about 300 B.C.) to the contemporary German stage director Peter Stein.

The chronological distribution in table 3 is divided into 4 categories with 1982 the most recent date cited. Three 30 -year periods (1982-1950, 1950-1920, and 1920-1890) account for the bulk of the references with a final pre- 1890 category for the remainder of the references. For convenience, the 377 references from the 1980 s, which account for $2 \%$ of all references, were included in the 1980-1950 category.

\section{Discussion}

The results shown in table 1 confirm that references to books strongly outnumber those to any other types of source. Indeed, in a survey review of eighteen recent Shakespeare monographs, critic Keith Brown acknowledges that the trend to publish books rather than journal articles may have gone too far, at least in Shakespearian studies, to the point of disqualifying the journal article as a means of disseminating research:

the cult of The Book is by now devaluing even collections of articles between hard covers, that traditional way of giving extra status to a good essay. Though article-references still pack the footnotes, book-length Shakespeare studies show increasing reluctance to engage fully with any previous work that was not itself presented in that form: thus pushing authors into seeking book-format even when some more economical form of publication might have served. ${ }^{10}$

This finding agrees with the author's earlier study of English and American monographs as well as with the articles on the journal literature of the humanities by David Baker, Richard Heinzkill, W. C. Simonton, and Madeline Stern. ${ }^{1}$ Indeed the proportion of references to books is markedly higher in this research project than in the author's previous work on the English and American monographic literature. It is, however, closer to the book percentages found in the studies of the humanities journal literature. Thus $81 \%$ of all references in English and in foreign languages were to monographs, while only $65.7 \%$ of the references in the author's earlier study were to books. Additional studies of the humanities journal literature found the following percentages of references to books: $82.7 \%$ for authors and $78.8 \%$ for literary movements in Stern's article; ${ }^{12}$ Heinzkill found $75 \%$ and Simonton $71.5 \%$ for the fine arts, ${ }^{13}$ and finally, D. L. Vaughan found 69.5 percent in musicology. ${ }^{14}$ 
In the present study, the number of references to journal articles and to manuscripts is very similar for prizewinning books $(8.4 \%$ for articles and $7.8 \%$ for manuscripts), but the notably higher percentages of references to journal articles (14.4\%) over those for manuscripts $(6.6 \%)$ for nonprizewinning books causes a higher total ranking for journal articles $(10.9 \%)$ than for manuscripts in the total sample $(7.3 \%)$. In the author's earlier study, $20.7 \%$ of the total had been to manuscript references as opposed to $13.3 \%$ to journal articles. Thus, it is apparent that the author of a monographic study is more apt to consult manuscript sources when preparing a journal article. The evidence of a lesser degree of such use of manuscripts for foreign literary topics by native speakers of English, who are in most cases based in the United States or United Kingdom, may reflect the greater expense and time required to go abroad to consult manuscript collections because many such sources are unavailable for loan or even photocopy.

Eight of the monographs had topics confined to the twentieth century, and another 8 considered some twentiethcentury topics or authors; some valuable material on some or all of these subjects probably remains unpublished. The lower use of manuscript sources in this study is not attributable to the fact that most worthwhile material on these topics has been published. While this claim might be made for older literary topics, comprehensive publication of all primary and most related secondary sources is unlikely for more contemporary topics, and other reasons must be sought to explain this reduced use of manuscript sources for foreign topics. In the earlier study of English and American literature, 18 books dealt wholly or in part with twentieth-century topics, but the number of manuscript references were three times more than this study.

In both of these studies of the humanities monographic literature, as in all the studies of the humanities journal literature, references to theses are negligible. Only 14 of the 30 books cited theses at all, and these references ranged from 1 to 32 in a single book, the next highest number being 12 . In all, there were 90 references to theses, $.49 \%$ of the total.

The same patterns of citation by type of source hold for both the total sample and the foreign references. Thus $81 \%$ of all references and $78.9 \%$ of all foreign references are to monographs, with these foreign references accounting for $46.4 \%$ of the total book references. Similar data may be observed for the other types of sources in table 1 .

There are fewer references to journal articles than in the author's previous study of the monographic literature: $10.9 \%$ as opposed to $13.3 \%$ of the earlier study of the English and American literary scholarship. These figures are even lower than those for the citation of journal articles in the humanities literature. Thus Stern found $15.1 \%$ citation to author articles and $16.5 \%$ citation to articles on literary movements. Simonton documented $28.6 \%$, Vaughan $25.3 \%$, and Heinzkill $19.9 \%$ citation to journal articles.

These figures seem to reflect a tendency toward less reliance on the journal literature together with a greater reliance on monographs by scholars researching books on foreign literary topics than is the case with either the monographic or the journal literature of English or American literary criticism.

The findings on the use of manuscripts and theses by scholars preparing books on foreign topics coincide more closely with those of previous studies of the journal literature of the humanities than to the author's previous study of humanities monographs. Baker's finding that $.83 \%$ of the items cited in his study of musicology were to theses is the highest such figure documented in the journal literature. ${ }^{16}$ The references to theses in the author's previous study were $.29 \%$ of the total. ${ }^{17}$

Though these findings for the citation of manuscript sources are lower than in the previous study, manuscript percentages are nonetheless higher than those for the journal literature of the humanities. The percentages of manuscript references in this study are notably higher than Stern's 
$2.2 \%$ for manuscripts to authors and $4.6 \%$ for manuscripts to literary movements; considering that this figure includes theses and encyclopedia articles as well as manuscript references, Stern's percentages would have been lower still had they applied exclusively to manuscripts. ${ }^{18}$ Baker found only $2.09 \%$ references to nonscore manuscripts and Vaughan only $5.2 \%{ }^{19}$

Table 2 shows the breakdown of references by individual foreign languages. The left half of the figure before the slash shows the named language's percentage of the total foreign tally; that on the right side of the slash contains the percentage that the language is of all references, both English and foreign. The figure in parentheses following this percentage lists the total number of references to that language. The foreign languages cited in this project are listed in descending order of mean percents based on the total sample. Thus, the most frequently cited foreign language in this study is French, with $31.2 \%$ of the total number of foreign references-3,714 out of a total of 11,843 foreign references. For the total sample, the percentage of French references is $20.1 \%$. French sources were cited in all of the prizewinners and fourteen of the nonprizewinners.

The rest of table 2 provides similar data for the other foreign languages encountered in this study. Two situations should be explained. German is ranked above Russian in table 2 somewhat arbitrarily because German was cited by more than three times the number of books citing Russian and thus had a higher mean percentage of all references. Russian, however, had a higher number of references because of three very heavily documented studies of Russian authors. The "other" category consists of languages cited in only a single book even though they may have been cited more frequently in that one book than other languages that were cited in a number of monographs. Danish with 410 references, Hebrew with 289, and Arabic with 241 make up the bulk of this category with only 33 additional references to other languages, 973 references in all, or $8.2 \%$ of the foreign and $5.3 \%$ of the total references.

For books that had no thematic concerns with the languages listed, the following percentages of references for three widely cited languages were found, based on the total number of references: $1.3 \%$ for French with 239 references, $1.3 \%$ for German (236 references), and .15\% (28 references) to Italian. Since all of these references were to secondary sources, barring the infrequent literary epigraph, clearly scholars cite only a minimum of secondary sources that are neither in their native languages nor that of the topic.

\section{"Heinzkill, in his study of the jour- nal literature of English literature, found only $9 \%$ of his citations were to foreign sources."}

Heinzkill, in his study of the journal literature of English literature, found only $9 \%$ of his citations were to foreign sources. ${ }^{20}$ Baker reported that $54.9 \%$ of the literature of musicology was in English, $29.9 \%$ in German, $9.9 \%$ in French, $5.5 \%$ in Italian, $2.2 \%$ in Latin, $1.1 \%$ in Russian, and $.65 \%$ in Spanish, with an additional $3.05 \%$ translations from foreign languages into English. ${ }^{21}$

The Hutchins study found the same ranking of languages in its survey of the language competency of British university professors in all disciplines as did this research. First in importance for humanists was French, with $65 \%$ of the scholars interviewed claiming fluency, $20.5 \%$ a reasonable reading knowledge, and $11.1 \%$ frequent use of a dictionary. For German, $24.8 \%$ claimed fluency, $16.2 \%$ a reasonable ease in reading, while $19.6 \%$ claimed frequent dictionary use. Russian claimed $4.3 \%$ were fluent, $2.6 \%$ had an adequate reading knowledge, and $3.4 \%$ made frequent use of a dictionary. ${ }^{22}$ Simonton found that scholars in the fine arts use English, German, and French sources in that order of frequency.

In a study of the historical literature, 
Jones found that only $7.7 \%$ of the citations were foreign (mainly German, Latin, and French), but that $55.1 \%$ of references in the fine arts and $42.7 \%$ of the references in music were foreign, whereas $89 \%$ of the citations for English history were to English-language sources. ${ }^{23}$

Lois Bebout, Donald Davie, Jr., and Donald Oehlert, in a study of interlibrary loan requests, reported that humanities scholars borrowed German, French, Spanish, and Italian materials, in that order. ${ }^{24}$ In a complex study of the citation of exclusively secondary sources in the journal literature of the humanities, M. S. Batts found that $65.8 \%$ of the citations were in French for English-language articles dealing with French topics with $31.67 \%$ in English and $2.5 \%$ in German. If the subject of an English-language study is German, $35.96 \%$ of the citations are in English, $5.42 \%$ in French, and $58.62 \%$ in German. ${ }^{25}$

Concerning translations, 4,745 quotations within the texts or in explanatory footnotes are translated into English in these books. Texts in Russian, Arabic, Hebrew, and Danish are quoted only in translation in this sample of books, though the texts are frequently cited in original-language editions in the notes. One prizewinning study of lyric poetry throughout the world drew on 13 separate literatures, but only $12.8 \%$ of its references were to foreign editions with another $18.1 \%$ of its references to translations. Fully $30.7 \%$ of all references in this study were to translated quotations, though in some cases the authors also included original texts.

Whether a reference was to a primary or a secondary source was considered. Such a breakdown can help determine if the greater emphasis on book sources is due to the heavy citation of primary sources, which are generally books or collected into books regardless of their origin as poems, short stories, essays, letters, or reviews. The reference pattern to primary sources was a very strong one. The total number of primary references was 9,005 out of a total of 18,481 references, $48.7 \%$ of the total. Stephen E. Wiberley, Jr., found that $65 \%$ of his citations were to primary sources and reports that Edwin Greaves found $60 \%$ of the citations in the literature of American literary studies to be primary. ${ }^{26}$

Self-citation has been prominently documented in the journal literature. Baker found that two-thirds of the articles he investigated feature self-citation. ${ }^{27}$ In this study, 18 of the 30 scholars cited their previous works. The number of self-citations per book ranged from 1 to 14 with the mean being 3.1. Only 6 authors cited themselves more than 5 times in the course of a monograph. The total number of self-citations was $92, .49 \%$ of the total references.

Table 3 shows the chronological breakdown of the topics of these books. The period of the topic obviously to some extent determines the span of time from which one draws on the secondary literature; a writer cannot quote Aristotle's opinion on Anouilh's Antigone, but can draw on the Greek philosopher's dicta on tragedy to support his or her views. On the other hand, as can be seen in table 3 and in the results of earlier studies of the literature of the humanities, the largest number of citations from critical works are drawn from the 20 years previous to publication of the work being written, though some highly regarded humanities criticism continues to be cited for up to 70 years. ${ }^{28}$ The period in which the literary subject originated structures the age of the citations to an extent not known in the sciences and social sciences, except for history. Scholars in all disciplines prefer recent critical literature to all but classic earlier criticism, particularly where journal articles are involved.

According to Eugene Garfield, one difference between scientific and humanistic literature is that even classic scientific papers become assimilated directly into the collective consciousness of a discipline and cease to be directly cited within five years. ${ }^{29}$ In the study of Shakespeare's Hamlet, however, Ben Jonson, Samuel Johnson, William Taylor Coleridge, A. C. Bradley, T. S. Eliot, A. L. Rouse, Jan Kott, and Terry Eagleton, spanning the periods from the mid-seventeenth century to the late twentieth century, may all be quoted and footnoted.

The data shown in table 3 are similar to 
those found in the author's study of the monographic literature of English and American literature. Both studies found a strong majority of references to be centered in the period since 1950 with a progressive drop in the number of references in each successive time period. The greatest concentration of monographic references fall after 1950, 66.5\% of all books. The corresponding figure for the study of English and American literary monographs was $61.7 \%$ for the total. ${ }^{30}$

While such a concentration of references might be anticipated for those books with twentieth-century topics, this pattern held for books with older topics as well. In fact, $44.3 \%$ of all references of books with nineteenth-century topics in the present study and $42.2 \%$ of the previous monographic study fell in the $1950-1980$ segment while $64.6 \%$ of books on seventeenth- and eighteenth-century topics were from this period; $53.6 \%$ of eighteenth-century and $64.9 \%$ of fourteenth- to seventeenth-century topics were also from the post-1950 period. Books with still older topics had $65.2 \%$ of their references in this period. For books with chronologically widespread topics, $69.2 \%$ of references fell in the $1950-1980$ period. The highest percentage of references to this most recent period was, not surprisingly, that of the books with exclusively twentieth-century topics; $76.7 \%$ of their references were post-1950. The greatest part $(68.7 \%)$ of all journal articles cited fell into this period, showing that older articles are less likely to be cited than more recent articles.

The percentages for foreign references shown in parentheses next to each figure in table 3 indicate what part of the total percentage of each period consisted of foreign references. Recalling that $64 \%$ of all references are foreign, one sees that patterns by decade for foreign references are very similar to those shown for the total sample: $23.8 \%$ of all foreign references date from after 1970 while $65.5 \%$ of all references occurred since 1950, of which $37.6 \%$ were foreign.

In succeeding periods the foreign percentages become ever closer to the total percentages, indicating that references to older foreign literary topics are predominantly to foreign sources at the same time that the number of references is dropping sharply. Thus $78.8 \%$ of all references from $1920-1950,80 \%$ of all $1890-1920$ references, and $77.1 \%$ of all pre-1890 references are to foreign sources. These percentages indicate that native speakers of English preparing studies on foreign literary topics not only use relatively little material more than 30 years old but also that they are unwilling to consult older materials to any great extent except for the primary foreign texts and a few classic secondary pieces. They are not consulting much secondary literature in English published before 1950; few of these earlier references are to English-language sources.

In this study, the most cited decade for the total sample was $1970-1980$ with $28.1 \%$ of the total references, declining to $23.3 \%$ for $1960-1970$, and $13.6 \%$ for 1950-1960. While there was little difference between the 1970-1980 decade (22.1\%) and the $1960-1970$ decade (23\%) for prizewinning books, nonprizewinning books showed a notably higher percentage of references for $1970-1980(28.4 \%)$ than for $1960-1970$ (22\%).

These patterns fit those of the journal literature of the various disciplines in the sciences, the social sciences, and the humanities found by Jones. They exhibit a wider spread of percentages of citations to recent publications: $34.9 \%$ of musicology, $22.8 \%$ of early modern English history, and $21.6 \%$ of United States history are 10 years old or less. ${ }^{31}$ In the present study, $27.1 \%$ of all references were 10 years old or less. For the early modern historical period, the authors found $75 \%$ of their journal citations postdated 1950. Heinzkill reported that about $40 \%$ of interlibrary loan requests for journal articles in English literary studies were for items 10 years old or less, and that $71 \%$ of all such journal requests were for materials published since $1945 .^{32}$ Stern wrote that about $60 \%$ of her citations were less than 20 years old and that $30.3 \%$ were 10 years old or less. ${ }^{33}$

A principal difference between this study of foreign monographs and the author's earlier study of English and American literary scholarship lies in the fact that 
nonprizewinning books do not exhibit marked deviations from the patterns of scholarly research from those established by prizewinning books as they had done in the earlier study. While nonprizewinning books still tend to be shorter with fewer references and to show a heavier concentration of their references in the most recent decades than do prizewinning books, these differences are less marked than was the case in the earlier study. In other aspects, the nonprizewinning monographs share the same patterns as prizewinners. The difference in patterns of citation for the individual foreign languages did not vary significantly except in those few cases when a random selection placed a book with an otherwise little-cited language in one group rather than the other.

The difference between these two studies may lie in the nature of scholarly publishing. Whereas in the earlier study there was a clearcut difference between the two groups in terms of publishers, that is not the case here. For the study of English and American literary scholarship, nonprizewinning books were generally published by presses that were neither associated with academic institutions nor the more respected trade presses. These books were often of an introductory nature with little to offer the professional scholar. In this study, however, university and major trade presses figure prominently in both groups of books.

The publishers for the nonprizewinners consist of 7 university presses, 4 specialized academic presses, a publisher specializing in short introductory texts, and a major trade press. For prizewinners in this study, there were 12 university presses and 3 major trade publishers. In the earlier study, the following published the prizewinners: 12 university presses, 2 major trade presses, and 1 specialized academic press. The nonprizewinners were published by the following: 3 by university presses, 4 by a press specializing in introductory texts, 2 by academic presses, 4 by major trade presses, and 2 by minor presses ( 1 of a semivanity nature).

\section{"Foreign literary studies in English are predominantly published by uni- versity or other academic presses, with only the exceptional title being published by major trade presses."}

Thus it seems that scholarship concerning foreign literature has fewer outlets for publication than do studies of American or English literature in terms of variety of presses. Foreign literary studies in English are predominantly published by university or other academic presses, with only the exceptional title being published by major trade presses.

\section{CONCLUSION}

Collection management officers and bibliographers concerned with the humanities find themselves facing different patterns of research than is the case in the sciences and social sciences. The principal tool of research for the humanities scholar is the recent monograph, not the journal article. Journal literature studies indicate that the book is the principal type of source in philosophy, the fine arts, and music, as well as in literary studies. Manuscripts are more frequently consulted in the humanities than in other disciplines, except for history with its use of archival materials. Theses and dissertations are generally ignored.

These two studies of the monographic literature of literary studies and the many studies of the journal literature of the humanities indicate that selectors for research collections must apply different standards in building collections in the humanities than those used in building social science and science collections. The ever-increasing tendency for major research libraries to allow their serial needs to dominate collection development must be resisted if scholars in the humanities are to be properly served. While the building of core collections of journals identified in the library literature for most disciplines is a necessity, it is impossible to 
build journal collections that fulfill all the needs of the researcher. No library can hope to subscribe to that minority of journals that will be wanted by scholars pursuing a seldom consulted byway of their topic. Interlibrary loan exists to supply such minority needs.

\section{"The ever-increasing tendency for major research libraries to allow their serial needs to dominate collection development must be resisted if scholars in the humanities are to be properly served."'}

Because current materials, particularly those $\mathbf{2 0}$ or fewer years old, are most heavily cited by humanities scholars, the most important task facing the selector in the humanities is the ongoing acquisition of the cream of each year's new publications from the academic presses and the identification and purchase of less selfrecommending titles from small presses, societies, academic departments, and museums. For many institutions, book budgets are sufficient to allow for, if not a comprehensive, at least a high research-level collection of currently published humanities monographs in English and in those foreign languages and programs most supported by the library.

This study has shown that there are fewer types of American and British publishers for monographic studies of foreign literary topics than for monographic studies of English or American literature. Statements by publishers indicate that foreign topics are not considered commercially viable propositions by most trade presses. This leaves the field to university presses that devote only a small part of their 70 annual publications to foreign topics and to small presses that publish even fewer titles and lack the advertising and distribution mechanisms of larger houses. Translations receive low priority for similar reasons. A reading knowledge of even the classical or modern West European languages is no longer assumed by authors or publishers writing for educated readers. In monographic studies of foreign literary topics by native speakers of English, the scholar will cite the original text and some secondary sources in the language of the text, but the bulk of the remaining references will be to Englishlanguage sources. Less than $2 \%$ of the references will be to sources in foreign languages other than that of the topic.

\section{REFERENCES AND NOTES}

1. John Cullars, "Characteristics of the Monographic Literature of British and American Literary Studies," College and Research Libraries 46:511-22 (Nov. 1985).

2. Herbert C. Morton and Anne Jamieson Price, "Views on Publication, Computers, Libraries," Scholarly Communication 5:10-14 (Summer 1986).

3. Clyven Jones, Michael Chapman, and Pamela Carr Woods, "Characteristics of the Literature Used by Historians," Journal of Librarianship 4:137-56 (July 1972).

4. Charles B. Osburn, Academic Research and Library Resources: Changing Patterns in America (Westport, Conn.: Greenwood, 1979).

5. Osburn, Academic Research, p.77.

6. W. T. Hutchins, L. J. Pargeter, and W. L. Saunders, "University Research and the Language Barrier," Journal of Librarianship 3:1-25 (Jan. 1971).

7. Earl Miner, "On the Desirability of Publishing Translations," Scholarly Publishing 11:291-99 (July 1980).

8. Kitty Harmon, "Translation Outlook: Bright or Dark?" Publishers Weekly 227:24 (Jan. 11, 1985).

9. Herbert S. Bailey, Jr., "Economics of Publishing in the Humanities," Scholarly Publishing 8:223-31 (Apr. 1977). 
10. Keith Brown, "Bringing Shakespeare to Book," TLS 4351:917-19 (Aug. 2, 1986).

11. David Baker, "Characteristics of the Literature Used by English Musicologists," Journal of Librarianship 10:182-209 (July 1978); Richard Heinzkill, "Characteristics of Reference in Selected Scholarly English Literary Journals," Library Quarterly 50:352-65 (July 1980); W. C. Simonton, "Characteristics of the Research Literature of the Fine Arts During the Period 1948-57" (Ph.D. diss., Univ. of Illinois, 1960), p.72-73; and Madeleine Stern, "Characteristics of the Literature of Literary Scholarship," College \& Research Libraries 44:199-209 (July 1983).

12. Stern, "Characteristics," p.199-209.

13. Heinzkill, "Characteristics," p.352-65.

14. D. L. Vaughan, "Characteristics of the Literature Cited by Authors in Articles in the Musical Quarterly, 1955-58, and the American Musicological Society Journal, 1953-56," (M.A. thesis, Univ. of North Carolina, 1959), p.57.

15. Cullars, "Characteristics," p.518.

16. Baker, "Characteristics," p.182-209.

17. Cullars, "Characteristics," p.516.

18. Stern, "Characteristics," p.204.

19. Cullars, "Characteristics," p.518.

20. Heinzkill, "Characteristics," p.361.

21. Baker, "Characteristics," p.192.

22. Hutchins, "University Research," p.4.

23. Jones, "Characteristics," p.152.

24. Lois Bebout, Donald Davie, Jr., and Donald Oehlert, "User Studies in the Humanities," RQ 15:40-44 (Fall 1975).

25. M. S. Batts, "Citation in the Humanities," IPLO Quarterly 4:20-40 (July 1972).

26. Stephen E. Wiberley, Jr., "Sources for the Humanities" in New Horizons for Academic Libraries: ACRL 1978, eds. Robert D. Stewart and Richard D. Johnson (New York: K. G. Saur, 1979), p.516-22.

27. Baker, "Characteristics," p.194.

28. R. M. Longyear, "Article Citations and Obsolescence in Musicological Journals," Notes 33:563-71 (Mar. 1971).

29. Eugene Garfield, "Is Information Retrieval in the Arts and Humanities Inherently Different from that in Science?" Library Quarterly 50:40-57 (Jan. 1980).

30. Cullars, "Characteristics," p.520.

31. Jones, "Characteristics," p.153.

32. Heinzkill, "Characteristics," p.207.

33. Stern, "Characteristics," p.207. 